\title{
RHEOLOGICAL, OPTICAL, AND BALLISTIC INVESTIGATIONS OF PARAFFIN-BASED FUELS FOR HYBRID ROCKET PROPULSION USING A TWO-DIMENSIONAL SLAB-BURNER
}

\section{Kobald ${ }^{1}$, E. Toson ${ }^{2}$, H. Ciezki ${ }^{1}$, S. Schlechtriem ${ }^{1}$, S. di Betta ${ }^{2}$, M. Coppola ${ }^{2}$, and L. DeLuca ${ }^{2}$}

${ }^{1}$ Deutsches Zentrum für Luft- und Raumfahrt (DLR) Institute of Space Propulsion Hardthausen D-74239, Germany

${ }^{2}$ Politecnico di Milano, Aerospace Engineering Department Space Propulsion Laboratory (SPLab) Milan I-20156, Italy

\begin{abstract}
This paper describes combined rheological, ballistic, and optical analyses performed on paraffin-based mixtures that can be used as high regression rate hybrid rocket fuels. Experimental activities have been done at the DLR Institute of Space Propulsion in Lampoldshausen and at SPLab of Politecnico di Milano [1]. Herein, the experiments that were performed at the DLR are described in detail. Viscosity, surface tension, and regression rate of the fuels have been determined. Furthermore, the combustion was evaluated by optical measurements. Data collected so far indicate an increasing regression rate for decreasing viscosity of the liquid paraffin which is in accordance with the current theories. Droplet entrainment, which is related to high regression rates, is only visible for the low-viscosity paraffin-based fuels.
\end{abstract}

\section{INTRODUCTION AND THEORY}

Hybrid rocket engines are said to combine the advantages of solid and liquid propulsion systems: simple and safe storability due to separately stored oxidizer and fuel, straightforward control of mixture ratio by variation of the oxidizer mass flow, and the possibility for immediate shutdown by closing the oxidizer's main valve. Compared to solids, they offer a higher specific impulse and thus more payload capability. Applications of hybrid rocket engines can be in small and medium sized sounding rockets or also as upper stages. Such programs 
exist in a large variety at different universities and companies worldwide. The inherent safety of hybrids makes them also attractive for manned flights. The most well-known example clearly shows the advantages and possibilities of hybrid rocket engines: Space Ship One by Scaled Composites achieved the first privately funded manned suborbital flight in 2004.

In the past, hybrid rocket engines have been blamed for their relatively low regression rate compared to solid rocket engines. For high thrust levels, long fuel grains with multiple ports are necessary which results in a low volumetric efficiency [2]. Carrick and Larson with colleagues evaluated cryogenic solid hybrid rocket fuels [3-5]. They used cryogenic solid $n$-pentane and measured regression rates 5-10 times higher than polymeric hybrid fuels. Following these studies, the tests have been done at Stanford University with hydrocarbons with longer chains that are solid at ambient temperature [6]. These fuels are paraffin-based hydrocarbons and show a regression rate 3 to 5 times higher than that obtained with conventional fuels. These high values are achieved by entrainment mass transfer. Normal polymeric fuels need to be fully vaporized or pyrolysed before being burned. Paraffin-based hydrocarbons form a melt layer on the surface on the fuel. From that layer, liquid droplets are entrained by liquid layer instabilities. Those are caused by the interaction of the high-velocity gas flow in the combustion chamber and the liquid melt layer [7]. For liquefying hybrids, the regression rate $\dot{r}$ is composed of two parts, namely, the classical regression rate $\dot{r}_{\text {vap }}$ consisting of the vaporizing fuel and an additional term $\dot{r}_{\text {ent }}$ which accounts for the mass transfer by entrainment:

$$
\dot{r}=\dot{r}_{\text {vap }}+\dot{r}_{\text {ent }} \approx 3: 5 \dot{r}_{\mathrm{HTPB}} .
$$

To account for the increased regression rate by entrainment, the classical hybrid combustion theory needs to be modified to consider the reduced heating of the entrained fuel, the reduced blocking effect due to two-phase flow, and the increased heat transfer due to the increased surface roughness. Through the entrainment, much more fuel can be transported into the flame zone before being totally vaporized. Scale-up tests have been done confirming that the theory is applicable also for large engines [8].

To quantify the value of the entrainment mass flow $\dot{m}_{\text {ent }}$, Karabeyoglu et al. [6] assume an empirical formula adapted from film cooling experiments with entrainment. It includes the dynamic pressure $p_{\text {dyn }}$, the thickness of the melt layer $h$, the surface tension $\sigma$, and the melt layer viscosity $\eta_{l}$ :

$$
\dot{m}_{\mathrm{ent}} \propto \frac{p_{\mathrm{dyn}}^{\alpha} h^{\beta}}{\eta_{l}^{\gamma} \sigma^{\pi}} .
$$

The upper part of Eq. (1) contains the operational parameter of the combustion, $p_{\text {dyn }}$, and indirectly the oxidizer mass flux. The lower part of Eq. (1) contains the material properties $\sigma$ and $\eta_{l}$ of the fuel. Literature values for the exponents 
Table 1 Entrainment exponent values

\begin{tabular}{lcccc}
\hline \multicolumn{1}{c}{ Reference } & $\alpha$ & $\beta$ & $\gamma$ & $\pi$ \\
\hline Gater and L'Ecuyer [9] & 1.5 & 2 & 1 & 1 \\
Nigmatulin et al. $[10]$ & 1 & 1 & - & - \\
Karabeyoglu et al. $[6]$ & $1-1.5$ & - & $>\pi$ & $<\gamma$ \\
\hline
\end{tabular}

of Eq. (1) are given in Table 1. The advantage of the entrainment mass flow is that it is not limited by the heat transfer to the fuel.

The exponents $\alpha$ and $\beta$ are believed to be between 1 and 2 whereas $\gamma$ and $\pi$ should be almost 1 . They also state that the melt layer viscosity should have a greater influence on the regression rate than the surface tension, meaning $\gamma>\pi$. The melt layer thickness $h$ can be solved explicitly according to Karabeyoglu et al. [6]. Assuming a black propellant that is absorbing all radiative heat transfer on the surface of the liquid melt layer, the melt layer thickness can be calculated as

$$
h=\delta_{l} \ln \left(1+\frac{C_{l} \Delta T_{1}}{h_{m}}\right) .
$$

The characteristic thermal thickness $\delta_{l}$ of the liquid layer is defined by the density of the liquid $\rho_{l}$ and solid paraffin $\rho_{s}$, the regression rate $\dot{r}$ and the thermal diffusivity of the liquid layer $\kappa_{l}$ as

$$
\delta_{l}=\frac{\kappa_{l} \rho_{l}}{\dot{r} \rho_{s}} .
$$

Karabeyoglu et al. compare the burning rate of their baseline mixture Paraffin Wax FR 5560 (SP-1a) with the burning rate of high-density polyethylene (HDPE) and two PE Waxes samples [11]. SP-1a achieves a 5 times higher regression rate than HDPE. The PE Waxes burn 2-3 times faster than HDPE. The viscosity data are not reported for all samples.

\subsection{Optical Investigations}

Nakagawa and Hikone did an investigation on the dependence of the regression rate on the fuel viscosity [12]. They investigated paraffin and oxygen as propellants in a two-dimensional (2D) slab burner with windows in the side for optical access [13]. They used pure paraffin and the same paraffin blended with different viscosities by adding $10 \%$ and $20 \%$ of ethylene-vinyl acetate. Tests were run at atmospheric pressure where they could show that droplets are generated during combustion and entrain in the flow. They assume the heat transfer coefficient $h$ as

$$
h=0.332 k^{2 / 3} c_{p l}^{1 / 3} \sqrt{\frac{u_{\infty} \rho_{l}}{x}} \eta^{-1 / 6} .
$$


Here, $k$ is the thermal conductivity; $u_{\infty}$ is the melted fuel general velocity; $\eta$ is the kinetic viscosity of the fuel, and $c_{p l}$ is the specific heat capacity of the liquid layer. This gives a relation of the heat transfer and regression rate to be proportional to $\eta^{-1 / 6}$. This would be a very weak dependence on the viscosity of $\dot{r}_{\text {ent }}$. Additionally, the mass flux of the tests was very low. The viscosities which were compared with the tests have been measured only at one temperature of $120^{\circ} \mathrm{C}$. But the average melt layer temperature is expected to be much higher [14]. Also, the temperature during combustion might be different and the viscosity depends on the temperature of the fuel.

Chandler et al. could also show droplet entrainment $[15,16]$. They used a 2D chamber with two windows at the side and one on top. Tests have been done with pure and blackened paraffin as well as with HDPE and hydroxyl-terminated polybutadiene (HTPB). For paraffin-based grains, small droplet entrainment was visible but no fine details with good resolution could be measured. For HDPE, they report that only little droplet entrainment was visible. They expected this due to the high viscosity of the liquid HDPE. For HTPB, no droplet entrainment could be measured.

DeLuca et al. also did an optical investigation of the hybrid combustion process with a novel technique. They look inside a pressurized chamber over a mirror setup inside the burning fuel grain and thereby measured the instantaneous regression rate [17].

\subsection{Paraffin Fuels}

Four different waxes are being researched as fuels. They are used in pure form as well as with different additives to modify mechanical and rheological properties. Their properties given from the manufacturer can be seen in Table 2. Type 6003 is a pure paraffin wax while type 0907 is a microcrystalline wax which is used, for example, in hot glues. Type 6805 has the same application but it is a paraffin wax. The last type 1276 is used for coatings, gloss, and sealing. Coatings manufactured with these waxes exhibit higher strength and, hence, abrasion resistance as well as an improved gloss impression. Its special formulation is based on waxes and a variety of different additives according to the manufacturer Sasol Wax.

Table 2 Wax properties given by manufacturer

\begin{tabular}{ccccc}
\hline $\begin{array}{c}\text { Sasol } \\
\text { wax }\end{array}$ & $\begin{array}{c}\text { Congealing point, } \\
{ }^{\circ} \mathrm{C}\end{array}$ & $\begin{array}{c}\text { Oil content, } \\
\%\end{array}$ & $\begin{array}{c}\text { Penetration at } 25{ }^{\circ} \mathrm{C}, \\
1 / 10 \mathrm{~mm}\end{array}$ & $\begin{array}{c}\text { Viscosity at } 100{ }^{\circ} \mathrm{C}, \\
\mathrm{mm}^{2} / \mathrm{s}\end{array}$ \\
\hline 6003 & $60-62$ & $0-0.5$ & $17-20$ & - \\
6805 & $66-70$ & $0-1$ & $16-20$ & $6-8$ \\
0907 & $83-94$ & $0-1$ & $4-10$ & $14-18$ \\
1276 & $64-68$ & - & $8-13$ & $880-920$ \\
\hline
\end{tabular}


These paraffin waxes have been tested in pure form and also mixed with $2 \%$ carbon black (CB) and $10 \%$ stearic acide (SA).

\section{EXPERIMENTS}

\subsection{Experimental Setup and Data Acquisition}

The burning rate tests of wax-based fuel formulations were evaluated in terms of regression rate values. Gaseous oxygen was used as the oxidizer. The experimental tests have been performed at the Institute of Space Propulsion at the DLR Lampoldshausen at test complex M11. An already existing modular combustion chamber was adjusted and used for the test campaigns $[18,19]$. This chamber has been designed and used in the past to investigate the combustion behavior of solid fuel ramjets. A rearward facing step before the fuel grain was used to provide adequate flame holding and assure combustion stability. A side view of the whole combustion chamber setup can be seen in Fig. 1. The oxidizer main flow is entering the combustion chamber from the left after having passed two flow straighteners. Ignition is done via an oxygen/hydrogen torch igniter from the bottom of the chamber. Two windows at each side enable several different optical diagnostic tools, which have already been performed successfully in the past during ramjet experiments. Previous test campaigns with this chamber have used the following methods to investigate the combustion behavior in solid fuel ramjets $[18,19]$ : a color schlieren setup was used to visualize the refractive index gradients in the chamber. These can be related in pure flows without combustion to the density gradients or species gradients. Particle image velocimetry (PIV) was used to get information about the flow field and velocity magnitudes. A coherent antistokes Raman spectroscopy (CARS) was applied there to get information about the temperature distribution. A gas sampling probe system was used to collect condensed combustion products and analyze them subsequently.

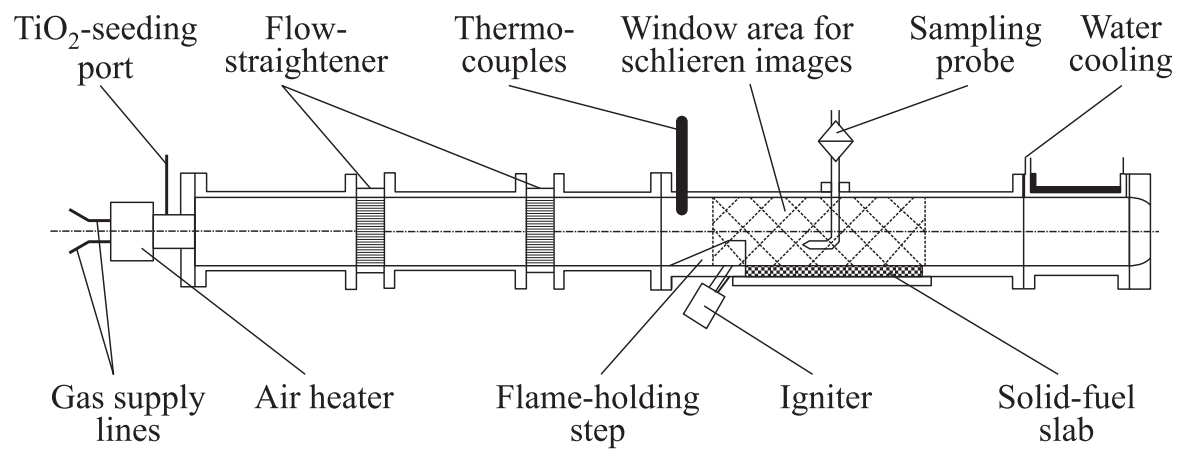

Figure 1 Sideview of combustion chamber setup 
Table 3 Automatic test sequence

\begin{tabular}{ll}
\hline Time, s & Action \\
\hline$t_{0}-30$ & Start of sequence \\
$t_{0}-29$ & Commanding control valve \\
$t_{0}-15$ & Set dome regulator pressures \\
$t_{0}-03$ & Start of data acquisition \\
$t_{0}-1$ & Start spark plug \\
$t_{0}-0.2$ & Open ignition valves \\
$t_{0}$ & Open oxidizer main valve, start of high-speed camera \\
$t_{0}+0.5$ & Close ignition valves \\
$t_{0}+5$ & Close oxidizer main valve, start nitrogen purge \\
$t_{0}+10$ & End of sequence \\
\hline
\end{tabular}

A test sequence is programmed before the test and is run automatically by the test bench control system. All tests have been done with the same settings shown in Table 3 . Each test duration is $5 \mathrm{~s}$. For redundancy, a separate measurement system is used for data acquisition during the tests. For this purpose, an ADwin measurement system by Jäger Messtechnik is used. Data acquisition on this measurement system was programmed by the proprietary software named ADbasic. All raw data are low-pass filtered via Dewetron signal amplifiers before the data acquisition. Depending on the sensor type that is used, a gain and

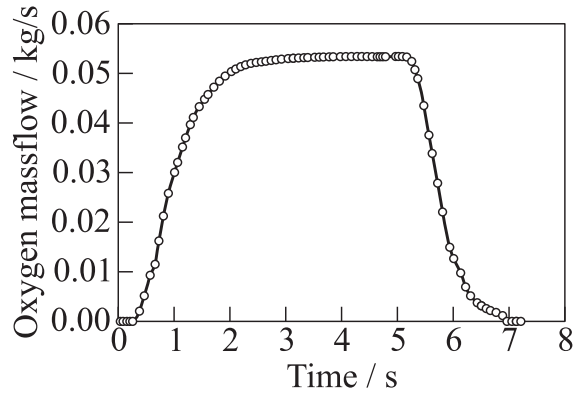

Figure 2 Typical oxidizer mass flow rate (Test 107) additional filters can be set to the signal if needed. The measured data are then routed from $\mathrm{ADwin}$ via Ethernet to a second PC which handles the data saving routines by a Labview program. For video data acquisition, a Photron Fastcam 1024 PCI high-speed videocamera is used with a maximum resolution of $1024 \times 1024$ pixel. The frame rate, resolution, and shutter time of the camera are adjusted for each test according to the test conditions and position of the camera.

The oxidizer mass flow rate is adjusted by a flow control valve. It is measured with a Coriolis flowmeter with an accuracy better than $0.35 \%$ and a repeatability better than $0.2 \%$ of the flow rate. A mass flow rate measurement of the oxidizer can be seen in Fig. 2. A steady-state mass flow rate of about $53 \mathrm{~g} / \mathrm{s}$ is set for all tests. Mass flow rate data are acquired in Labview via a digital protocol. The tests are done at atmospheric pressure. 


\subsection{Viscosity Measurements}

The viscosity of a fluid defines its resistance to deformation by external forces like shear stress or tensile stress. The viscosity in Eq. (1) is expected to have the greatest influence on $\dot{m}_{\text {ent }}$. For this reason, the viscosity of fuels in these tests is evaluated in detail and will be compared with the regression rate results from the burning rate tests. The relation between the viscosity $\eta(\dot{\gamma})$, the shear rate $\dot{\gamma}$, and the shear stress $\tau(\dot{\gamma})$ is described by

$$
\tau(\dot{\gamma})=\eta(\dot{\gamma}) \dot{\gamma}
$$

The viscosity measurements have been done with a Haake RheoStress 6000 rotational rheometer with a plate-plate and cone-plate geometry. The measurement range is between $10^{-7}$ and $1500 \mathrm{~min}^{-1}$ at constant shear or at constant rotation. The frequency range is between $10^{-5}$ and $100 \mathrm{~Hz}$. A measurement of the viscosity of the pure waxes at different shear rates was done before each test and can be seen in Fig. 3. Then, a shear rate for the temperature ramp measurement was chosen where the waxes are still in the linear viscoelastic range. In Fig. 4, the measurement of viscosity depending on the temperature is shown. Tests have been done starting from $200{ }^{\circ} \mathrm{C}$ down to the solidification point of the paraffin samples.

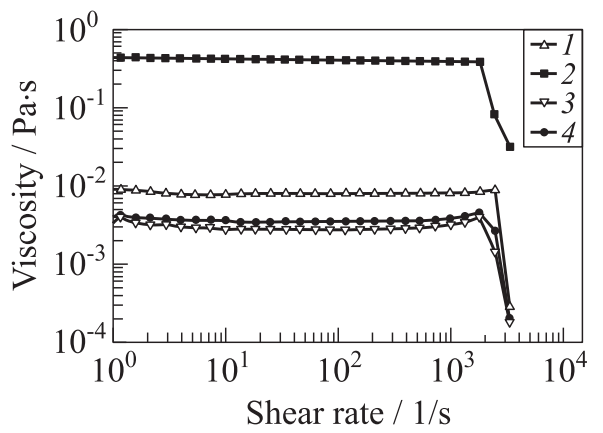

Figure 3 Comparison viscosity vs. shear rate of pure paraffin at $T=120{ }^{\circ} \mathrm{C}: 1-$ Sasol wax 0907; 2 - Sasol wax 1276; 3 Sasol wax 6003; and 4 - Sasol wax 6805
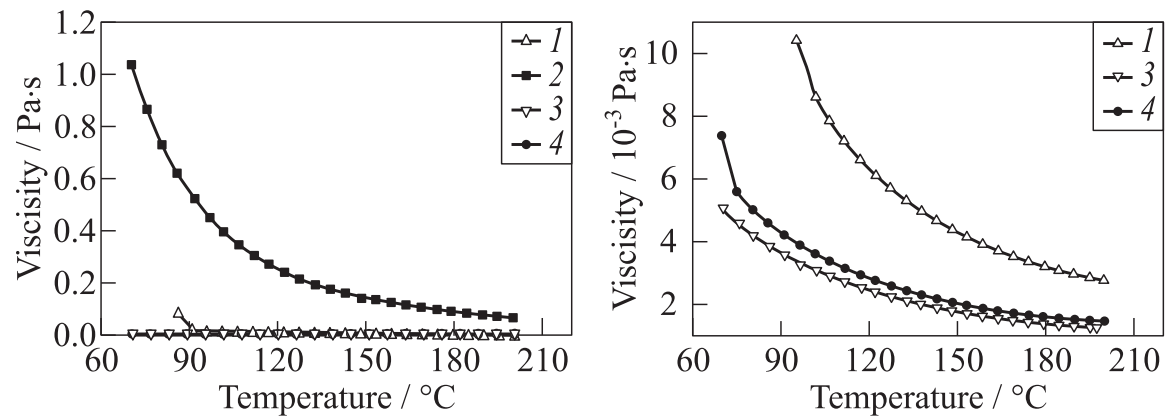

Figure 4 Comparison viscosity of pure paraffin $(\gamma=501 / \mathrm{s}): 1-$ Sasol wax 0907; 2 - Sasol wax 1276; 3 - Sasol wax 6003; and 4-Sasol wax 6805 


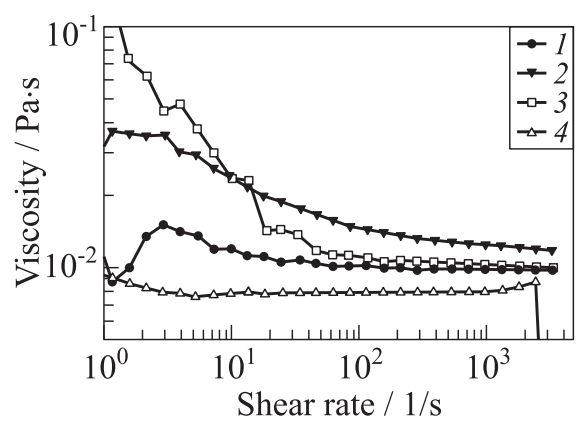

Figure 5 Comparison viscosity vs. shear rate of $0907+\mathrm{CB}+\mathrm{SA}$ with different percentage of $\mathrm{CB}$ at $T=120{ }^{\circ} \mathrm{C}$ : 1 - Sasol wax $+1.5 \% \mathrm{CB} ; 2$ - Sasol wax $+1.8 \% \mathrm{CB} ; 3-$ Sasol wax $+2 \% \mathrm{CB}$; and 4 - Pure

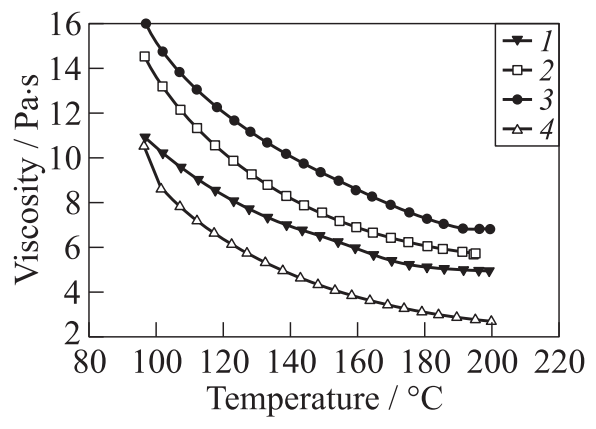

Figure 6 Comparison viscosity of $0907+\mathrm{CB}+\mathrm{SA}$ with different percentage of $\mathrm{CB}(\dot{\gamma}=501 / \mathrm{s}): 1-$ Sasol wax $+1.8 \% \mathrm{CB} ; 2-$ Sasol wax $+2 \% \mathrm{CB}$; 3 - Sasol wax $+3 \% \mathrm{CB}$; and $4-$ Pure

The viscosities of each type seem to reach asymptotic values at higher temperatures but the exact value cannot be clearly determined [20]. Thus, it is difficult to choose the viscosity at an average temperature between the melting and boiling temperature which could be used for Eq. (1). The boiling and average temperature can be calculated, for example, with equations from Marano and Holder [21].

The pure paraffin samples investigated here show a Newtonian behavior, which means that the measured viscosity is independent of the applied shear rate. For the mixtures with $\mathrm{CB}$ and $\mathrm{SA}$, a non-Newtonian behavior is measured for percentages of $\mathrm{CB}$ greater than $1.5 \%$. This can be seen in Fig. 5. The influence of the $\mathrm{CB}$ percentage to the viscosity is shown in Fig. 6. Viscosity is increasing with increasing CB percentage. The influence of the $10 \% \mathrm{SA}$ addition on the viscosity in the mixed paraffin samples has also been measured. The change in viscosity compared to the pure paraffin samples was negligible.

Table 4 Average difference between measured viscosity of pure paraffin compared with 6003

\begin{tabular}{cc}
\hline Sasol wax & $\Delta \eta, \%$ \\
\hline Pure 6003 & 0 \\
Pure 6805 & 17.99 \\
Pure 0907 & 156.72 \\
Pure 1276 & 10,707 \\
\hline
\end{tabular}

In Table 4, the differences in viscosity of the samples are compared. One can see that type 1276 has a viscosity two orders of magnitude higher than type 6003. Type 0907 has a 156.72 percent increase and 6805 a 17.99 percent increase compared to 6003 .

Table 5 lists the differences in viscosity of the paraffin mixtures. Due to the non-Newtonian behavior, one has different viscosities of the same mixture at different shear rate settings. 
Table 5 Average difference between measured viscosity of paraffin $+\mathrm{CB}+\mathrm{SA}$ compared with pure type at different shear rates

\begin{tabular}{ccc}
\hline Sasol wax & Shear rate $\dot{\gamma}, 1 / \mathrm{s}$ & $\Delta \eta, \%$ \\
\hline \multirow{2}{*}{$6003+\mathrm{CB}+\mathrm{SA}$} & 300 & 41.81 \\
& 500 & 44.87 \\
& 1000 & 42.26 \\
\hline \multirow{2}{6}{$6805+\mathrm{CB}+\mathrm{SA}$} & 300 & 37.02 \\
& 500 & 46.72 \\
& 1000 & 33.58 \\
\hline \multirow{2}{0}{$0907+\mathrm{CB}+\mathrm{SA}$} & 300 & 53.81 \\
& 500 & 63.93 \\
& 1000 & 34.37 \\
\hline \multirow{2}{*}{$1276+\mathrm{CB}+\mathrm{SA}$} & 300 & 36.37 \\
& 500 & 30.55 \\
& 1000 & 33.33 \\
\hline
\end{tabular}

\subsection{Surface Tension Measurements}

Surface tension is the property of a liquid to resist against an external force applied to it. It is caused by the cohesion force of similar molecules. Surface tension depends strongly on the temperature with a linear relation. Empirical correlations like the Eötvös rule use the critical temperature, the molar volume, and the molar surface tension to calculate the surface tension of pure liquids at a certain temperature. Another relation that can be used is from Guggenheim-Katayama. For the present experiments, a Krüss EasyDyne tensiometer was used to measure the surface tension $\sigma$ of the waxes. The measurement range is from 1 to $999 \mathrm{mN} / \mathrm{m}$ with an accuracy of $\pm 0.1 \mathrm{mN} / \mathrm{m}$. Figure 7 shows the measured surface tension values of Sasol 6003 as an example at different temperatures. About 35-40

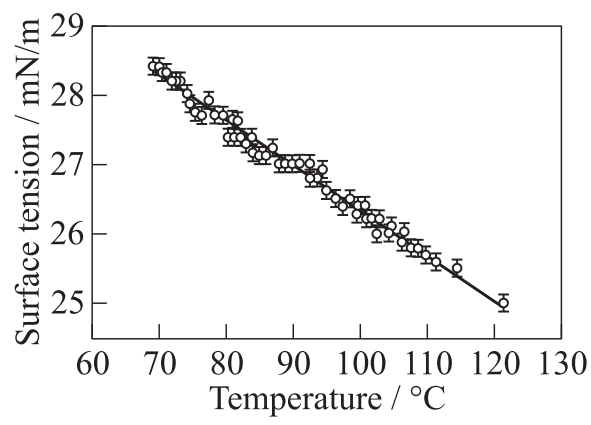

Figure 7 All measurements (signs) of Sasol 6003 surface tension; line - linear regression measurements for each sample have been taken at decreasing temperature. The starting temperature of the paraffin samples was approximately $130{ }^{\circ} \mathrm{C}$. Then, the measurements have been taken while the sample was cooling down until it started to solidify. A best-fit line 
Table 6 Comparison surface tension of pure paraffin at $100{ }^{\circ} \mathrm{C}$

\begin{tabular}{cccc}
\hline Sasol wax & $\sigma, \mathrm{mN} / \mathrm{m}$ & $\Delta \sigma, \%$ & $\Delta \sigma$ at $T_{\mathrm{av}}, \%$ \\
\hline Pure 6003 & 26.32 & 0 & 0 \\
Pure 6805 & 26.88 & 2.08 & 0.87 \\
Pure 0907 & 28.28 & 6.9 & -31.89 \\
Pure 1276 & 29.09 & 9.5 & 28.18 \\
\hline
\end{tabular}

Table 7 Measured surface tension values at $100{ }^{\circ} \mathrm{C}$

\begin{tabular}{lccc}
\hline \multicolumn{1}{c}{ Formulation } & $\sigma, \mathrm{mN} / \mathrm{m}$ & $\Delta \sigma, \%$ & $\Delta \sigma$ at $T_{\mathrm{av}}, \%$ \\
\hline Pure 6003 & 26.32 & 0 & 0 \\
$6003+1 \% \mathrm{CB}$ & 26.49 & 0.65 & 0.50 \\
$6003+10 \% \mathrm{SA}$ & 26.35 & 0.11 & -5.19 \\
$6003+10 \% \mathrm{Al}$ & 26.45 & 0.49 & 2.84 \\
\hline Pure 6805 & 26.88 & 0 & 0 \\
$6805+1 \% \mathrm{CB}$ & 26.95 & 0.26 & -0.98 \\
$6805+10 \% \mathrm{SA}$ & 26.73 & -0.56 & -15.69 \\
\hline Pure 0907 & 28.28 & 0 & 0 \\
$0907+2 \% \mathrm{CB}$ & 27.71 & -2.02 & 19.51 \\
$0907+10 \% \mathrm{SA}$ & 27.82 & -1.63 & 16.42 \\
$0907+10 \% \mathrm{Al}$ & 27.69 & -2.09 & 7.17 \\
\hline Pure 1276 & 29.09 & 0 & 0 \\
$1276+1 \% \mathrm{CB}$ & 28.71 & -1.31 & -2.65 \\
$1276+10 \% \mathrm{SA}$ & 28.29 & -2.75 & -16.63 \\
\hline
\end{tabular}

was calculated to get a linear relation and extrapolate the surface tension values at $T_{\mathrm{av}}$ in Tables 6 and 7 ( $T_{\mathrm{av}}$ is the average temperature between the melting temperature $\left(\approx 60-94{ }^{\circ} \mathrm{C}\right.$, see Table 2$)$ and boiling temperature $\left(\approx 450{ }^{\circ} \mathrm{C}\right)$ of the individual paraffin type). Table 6 shows a comparison of the surface tension values of the pure substances. The change $\Delta \sigma$ is calculated by comparison with the value from type 6003 .

Figure 8 shows the best-fit lines of all pure Sasol waxes. It can be seen that type 6003 and 6805 have about the same negative slope of the curve and also approximately the same value of surface tension with only 2.08 percent difference (see also Table 6). Type 0907 has a smaller negative slope as 6003 and, therefore, the value of surface tension at $T_{\mathrm{av}}$ in Table 6 is $-31.89 \%$ lower than that of 6003 . At $100{ }^{\circ} \mathrm{C}$, the increase in surface tension is about $6.9 \%$ compared to 6003 . In contrast, type 1276 has a slightly bigger negative slope which results in a 28.18 percent increase in surface tension at $T_{\text {av }}$, compared to a 9.5 percent increase at $100{ }^{\circ} \mathrm{C}$. Looking back at Eq. (1), it should be reminded that an increase in surface tension would result in a decrease in $\dot{r}_{\text {ent }}$. 
An overview about the measured surface tensions of the paraffin waxes with different additives at $100{ }^{\circ} \mathrm{C}$ is shown in Table 7 [22]. The surface tension at the average temperature $T_{\text {av }}$ between the melting and boiling temperature of paraffin is also extrapolated from the measured data and the deviation from the pure formulation is calculated.

Comparing the surface tension in Table 7 , one can see that the differences are smaller than $3 \%$ between the pure formulations and

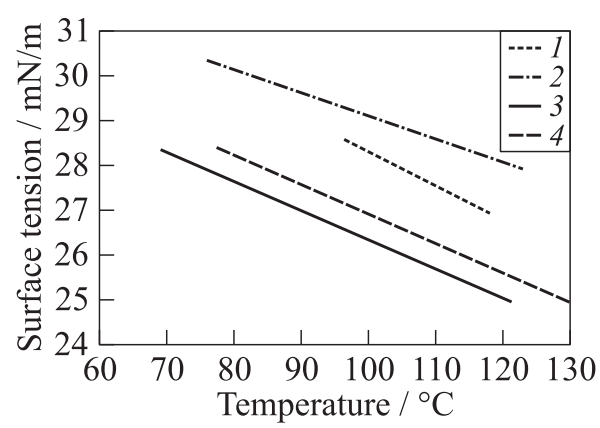

Figure 8 Surface tension averaged of all samples: $1-0907 ; 2-1276 ; 3-6003$; and $4-6805$ those with additives at $100{ }^{\circ} \mathrm{C}$. At $T_{\mathrm{av}}$, the differences are bigger. Stearic acide decreases the surface tension for 6003,6805 and 1276 while an increase of $16.42 \%$ is measured for 0907 . For CB, one has small changes in surface tension with 6003, 6805, and 1276 while 0907 has a 19.51 percent increase in surface tension. Addition of $10 \% \mathrm{Al}$ gives only a 2.84 percent increase for 6003 while one gets 7.17 percent increase for 0907 . One can see that for some additives, the surface tension at extrapolated temperature is changed up to $20 \%$. This would also result in a change in $\dot{r}_{\text {ent }}$ assuming that Eq. (1) and its exponents from Table 1 are valid.

\subsection{Regression Rate}

The reason to use a $2 \mathrm{D}$ fuel slab was primarily to get an insight into the combustion process above the fuel surface. The regression rates with this setup have also been measured but they should not be compared directly with data from cylindrical fuel grains. With the $2 \mathrm{D}$ slab, the convective and radiative heat fluxes are different. Much more heat is lost to the surroundings like the Quartz glass windows and the upper metallic surface of the combustion chamber. Thus, less heat is transferred to the fuel and the regression rates measured are lower than with cylindrical fuel grains.

The fuel mass flow $\dot{m}_{f}$ from the solid fuel into the combustion zone is defined by the heat of vaporization of the fuel and the total heat transfer by convection and radiation into the fuel. It is proportional to fuel's density $\rho_{f}$, its surface area $A_{S}$, and the regression rate $\dot{r}$ :

$$
\dot{m}_{f}=\rho_{f} A_{S} \dot{r} .
$$




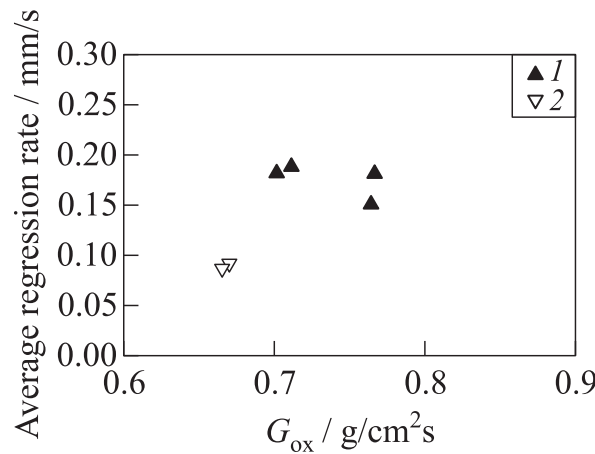

(a)

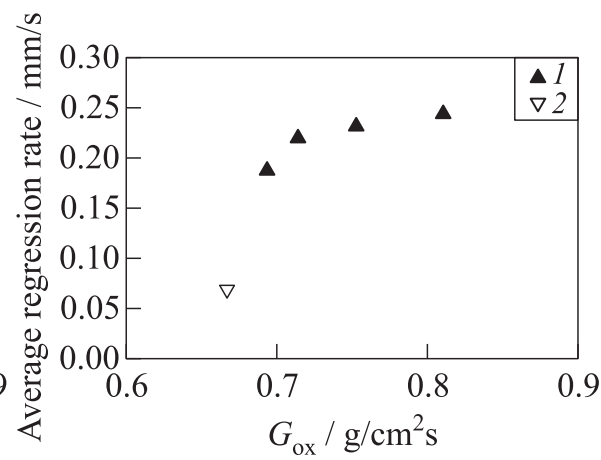

(b)

Figure 9 Comparison between regression rates of big (1) and small (2) fuel slabs of $0907(a)$ and $6805(b)$

The regression rate $\dot{r}$ in a hybrid rocket engine is described with the oxidizer mass flux $G_{\text {ox }}$ by

$$
\dot{r}=a G_{\mathrm{ox}}^{n} .
$$

The fuel slabs being used have a length of about $180 \mathrm{~mm}$, width of $90 \mathrm{~mm}$, and height of $18 \mathrm{~mm}$. The leading edge upstream has an angle of about $20^{\circ}$ with a length of $50 \mathrm{~mm}$. The tests have also been done with smaller slabs with dimensions of length of about $100 \mathrm{~mm}$, width of $70 \mathrm{~mm}$, and height of $14 \mathrm{~mm}$. The regression rate values shown are space- and time-averaged. A measurement uncertainty during the tests is that some paraffin is flowing down beneath the fuel slab in the chamber. This fuel is not burning and remains in the chamber. Thus, this residual is collected after the test and is considered for the mass loss. For Paraffin 0907 and 6805, different tests with both fuel slab sizes can be seen in Fig. 9. For 0907, the big fuel slabs show about twice the regression rate of the small slabs at similar oxidizer mass flux. For 6805, the difference is almost 3-4 times. The reason for this lies in the different oxidizer mass flow to fuel mass flow ratios (ROF) during the tests with the small and the big slabs. For the big slab, the ROF is between $5-15$ whereas for the small slabs, the ROF is much higher, up to 70 . When the combustion temperature is computed for 0907 with CEA for different ROF, one gets a graph like in Fig. 10. There one can see that the maximum temperature is at the stoichiometric ratio between 2 and 3 and the temperature is decreasing rapidly for higher ROF. Thus, for higher ROF, less heat can be transferred to the solid fuel and the regression rate decreases. Therefore, care must be taken to compare regression rates of the fuels at similar ROF. Karabeyoglu et al. propose a correction for this effect based on the regression rate constants and the $\mathrm{ROF}[8,23]$. The effect of increasing ROF can also be seen in Fig. $9 b$ for the big slab 6805 . The tests with big fuel slab 
shown have been done one after each other using the same slab. The highest regression rate $0.24 \mathrm{~mm} / \mathrm{s}$ corresponds to an ROF of about 7 . Then, the regression rate decreases as ROF increases. At $0.23 \mathrm{~mm} / \mathrm{s}$, one has an $\mathrm{ROF}$ of 8.2 . The smallest value $0.19 \mathrm{~mm} / \mathrm{s}$ had an ROF of 13.2 .

An overview about the averaged regression rates of all tests with big fuel slabs and similar ROF can be seen in Fig. 11. Here, one can see that paraffin 6003 with the lowest

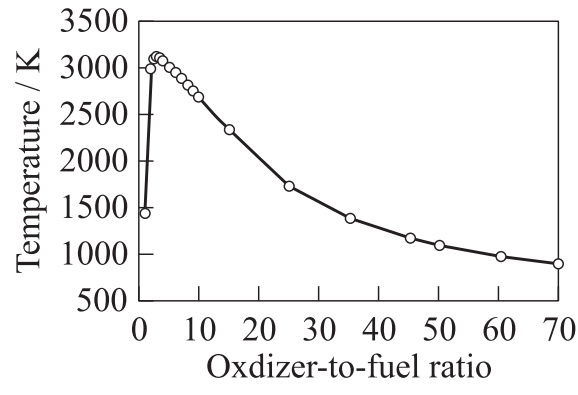

Figure 10 Combustion temperature vs. ROF of 0907 viscosity shows the highest regression rate. This is valid for the pure sample and, also, for the mixture with CB and SA, where the mixtures have a higher viscosity. Furthermore, the regression rates are decreasing as the viscosity values of the paraffin samples are increasing (see also Tables 4 and 5). Type 1276 with its very high viscosity shows regression rate values as low as HTPB values measured at SPLab at similar mass flux [1]. When looking at Table 6 , one sees that the difference in surface tension compared to the fastest burning paraffin type 6003 is only $9.5 \%$. Thus, one can conclude that a low viscosity has a much higher influence on the entrainment mass flow than a low surface tension.

The importance of the viscosity gets more clear if, one looks at Table 8 . There, the average of all regression rate values from Fig. 11 is computed. One can see that type 6003 with the lowest viscosity achieves the highest regression

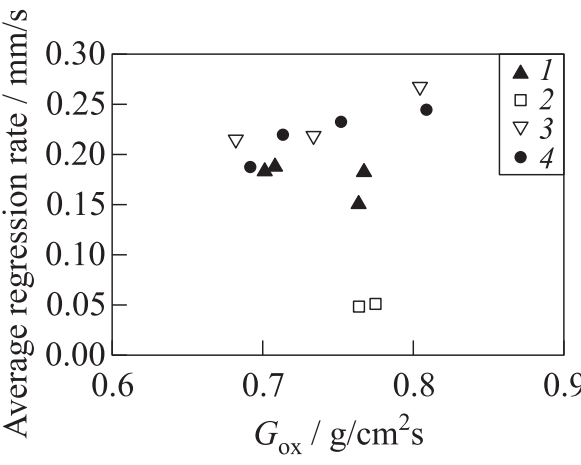

(a)

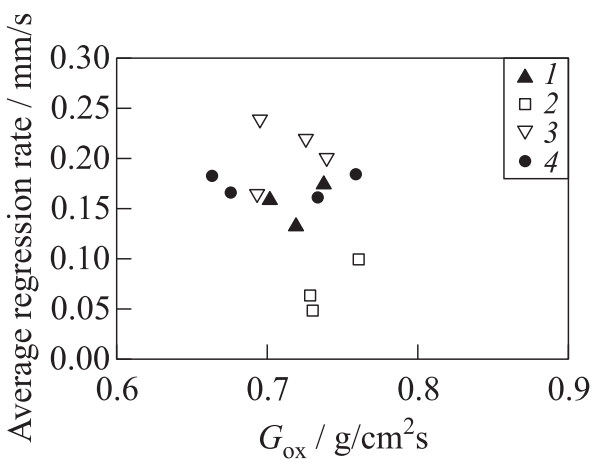

(b)

Figure 11 Comparison regression rate of pure paraffin $(a)$ and mixtures with $\mathrm{CB}$ and SA $(b): 1-0907 ; 2-1276 ; 3-6003 ;$ and $4-6805$ 
Table 8 Comparison average regression rates of pure paraffin and paraffin with $\mathrm{CB}$ and SA

\begin{tabular}{cccc}
\hline Sasol wax & $\dot{r}, \mathrm{~mm} / \mathrm{s}$ & $\Delta \dot{r}_{\text {pure }}, \%$ & $\Delta \eta, \%$ \\
\hline 6003 & 0.232 & 0 & 0 \\
6805 & 0.220 & -5.55 & 17.99 \\
0907 & 0.175 & -24.61 & 156.72 \\
1276 & 0.050 & -78.61 & 10,707 \\
\hline $6003+\mathrm{CB}+\mathrm{SA}$ & 0.204 & 0 & 0 \\
$6805+\mathrm{CB}+\mathrm{SA}$ & 0.173 & -15.35 & 15.41 \\
$0907+\mathrm{CB}+\mathrm{SA}$ & 0.154 & -24.64 & 168.76 \\
$1276+\mathrm{CB}+\mathrm{SA}$ & 0.070 & -65.70 & 10,188 \\
\hline
\end{tabular}

Table 9 Comparison average regression rates between pure paraffin and paraffin with $\mathrm{CB}$ and SA

\begin{tabular}{cccc}
\hline Sasol wax & compared with & $\Delta \dot{r}, \%$ & $\Delta \eta, \%$ \\
\hline 6003 & $6003+\mathrm{CB}+\mathrm{SA}$ & 24.9 & 41.81 \\
6805 & $6805+\mathrm{CB}+\mathrm{SA}$ & 22.3 & 37.02 \\
0907 & $0907+\mathrm{CB}+\mathrm{SA}$ & 11.8 & 53.81 \\
1276 & $1276+\mathrm{CB}+\mathrm{SA}$ & -32.6 & 36.37 \\
\hline
\end{tabular}

rates. The difference $\Delta \dot{r}_{\text {pure }}$ in regression rate uses the value of pure 6003 for the pure paraffins. Concerning the mixtures, the formulation of $6003+\mathrm{CB}+\mathrm{SA}$ is chosen as reference. The same applies for the change in viscosity $\Delta \eta$. The change in viscosity and regression rate of the paraffin samples due to the addition of CB and SA is shown in Table 9.

\subsection{Optical Investigations}

\subsubsection{Ignition delay}

From the video data, the ignition behavior has also been analyzed. The tests with 5000 FPS recording rate and similar shutter settings have been chosen (Table 10). The appearance of the first flame corresponds to the ignition of the oxygen/hydrogen torch igniter. Then, the time of the first flame on top of the fuel slab is considered as time when the fuel slab starts to ignite. The time difference between these two is listed as the ignition delay. Finding the ignition time of the fuel is sometimes difficult because the igniter also illuminates the picture and the flame of the paraffin is not very bright initially. Generally, it seems that the pure paraffin samples ignite faster than the mixtures, after about 0.1 to $0.2 \mathrm{~s}$. For 
Table 10 Ignition delay of the different paraffin samples

\begin{tabular}{|c|c|c|c|c|c|}
\hline Sasol wax & $\begin{array}{l}\text { Test } \\
\text { No. }\end{array}$ & $\begin{array}{c}\text { Igniter time, } \\
\mathrm{s}\end{array}$ & $\begin{array}{c}\text { Fuel ignition, } \\
\mathrm{s}\end{array}$ & $\begin{array}{l}\text { Ignition delay, } \\
\mathrm{s}\end{array}$ & Shutter \\
\hline \multirow{4}{*}{ Pure 6003} & 075 & 0.47 & 0.74 & 0.27 & $1 / 40,000$ \\
\hline & 126 & 0.46 & 0.60 & 0.14 & $1 / 40,000$ \\
\hline & 076 & 0.17 & 0.30 & 0.13 & $1 / 72,000$ \\
\hline & 128 & 0.47 & 0.64 & 0.17 & $1 / 106,000$ \\
\hline \multirow{3}{*}{ Pure 6805} & 106 & 0.18 & 0.30 & 0.13 & $1 / 41,000$ \\
\hline & 108 & 0.18 & 0.33 & 0.15 & $1 / 41,000$ \\
\hline & 107 & 0.18 & 0.32 & 0.14 & $1 / 106,000$ \\
\hline \multirow{3}{*}{ Pure 0907} & 081 & 0.16 & 0.30 & 0.14 & $1 / 40,000$ \\
\hline & 089 & 0.18 & 0.26 & 0.08 & $1 / 40,000$ \\
\hline & 080 & 0.17 & 0.30 & 0.11 & $1 / 75,000$ \\
\hline \multirow{3}{*}{ Pure 1276} & 109 & 0.22 & 0.34 & 0.12 & $1 / 41,000$ \\
\hline & 112 & 0.29 & 0.42 & 0.13 & $1 / 106,000$ \\
\hline & 113 & 0.14 & 0.27 & 0.13 & $1 / 106,000$ \\
\hline \multirow{2}{*}{$6003+\mathrm{CB}+\mathrm{SA}$} & 096 & 0.17 & 0.64 & 0.47 & $1 / 41,000$ \\
\hline & 095 & 0.18 & 0.64 & 0.46 & $1 / 106,000$ \\
\hline \multirow{3}{*}{$6805+\mathrm{CB}+\mathrm{SA}$} & 082 & 0.19 & 0.60 & 0.31 & $1 / 40,000$ \\
\hline & 084 & 0.15 & 0.37 & 0.22 & $1 / 40,000$ \\
\hline & 085 & 0.15 & 0.38 & 0.23 & $1 / 105,000$ \\
\hline \multirow{2}{*}{$0907+\mathrm{CB}+\mathrm{SA}$} & 097 & 0.19 & 0.84 & 0.65 & $1 / 41,000$ \\
\hline & 098 & 0.31 & 0.63 & 0.32 & $1 / 106,000$ \\
\hline \multirow{3}{*}{$1276+\mathrm{CB}+\mathrm{SA}$} & 090 & 0.18 & 0.28 & 0.10 & $1 / 41,000$ \\
\hline & 092 & 0.22 & 0.32 & 0.10 & $1 / 106,000$ \\
\hline & 093 & 0.20 & 0.34 & 0.14 & $1 / 106,000$ \\
\hline
\end{tabular}

the mixtures, the ignition delay is higher, between 0.22 and about $0.5 \mathrm{~s}$. Only the samples 1276 in pure and mixed form seem to ignite after the same delay of only $0.1 \mathrm{~s}$. Additionally, the flame of type 1276 appeared brighter and thicker compared to the other samples. This might also lead to an earlier visibility of the first flame and, thus, apparently a shorter ignition delay.

\subsubsection{Combustion behavior}

The burning rate tests have been recorded with a high-speed camera to get more knowledge about the combustion process. All images are recorded with the oxidizer flow direction from left to right. Figure 12 shows the entrainment process in good detail. The image is taken during the ignition phase of test 169 at $T=0.424 \mathrm{~s}$. In the video, a lot of very fine droplets can be seen which are released from all along the surface of the fuel. Droplets are released also from the waves rolling over the fuel surface. This is in accordance with the theory of 


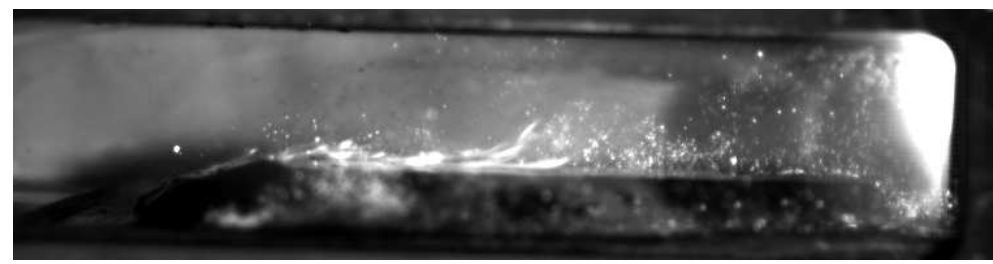

Figure 12 Image of $6805+2 \% \mathrm{CB}+10 \% \mathrm{SA}$ during ignition at $T=0.424 \mathrm{~s}$ of test 169 (6000 FPS, frame 2542)

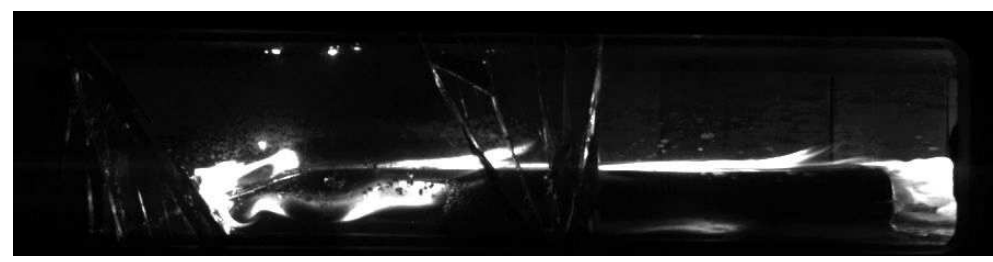

Figure 13 Image of $6003+2 \%$ CB $+10 \%$ SA during test 96 (5000 FPS, frame 11,548)

the liquid layer Kelvin-Helmholtz instability [7]. The droplet entrainment is not stationary, but appears rather periodically. A huge burst of droplets entraining is followed by a slight decrease and then again a burst of more droplets.

For all tests, a wave like flame structure can be seen in the high-speed video data. Figure 13 shows an image of test 096 during combustion. The flame is turbulent and not stationary. One can see a roll up of the flame at start of the fuel grain and then the flame is moving along on top of the fuel. About 24 single large-scale waves can be seen on top of the fuel at one frame during steady state. The rotation of a vortex after the flame-holding step can also be seen. The step generates a small flame in front of the fuel which is burning continuously. The appearance of the long wave like structures on top of the fuel seems related with the vortex shedding after the step. The influence of the rearward facing step in the precombustion chamber is currently in progress. More results are shown in [24]. The lines in Fig. 13 in the middle of the image are cracks in the glass due to a hard ignition in a previous test. Waves during the combustion of paraffin have also been seen by Kim et al. [25]. But they were able to measure strong droplet entrainment only during nonreacting hotgas injection. Optical experiments by Nakagawa and Hikone could also only show minor droplet entrainment but no details on the roll wave instabilities [12].

Due to the high shutter settings, droplet formation seems only visible during the ignition transients. When the igniter starts burning and the paraffin is not yet fully ignited, many droplets can be seen being released mainly from the area 


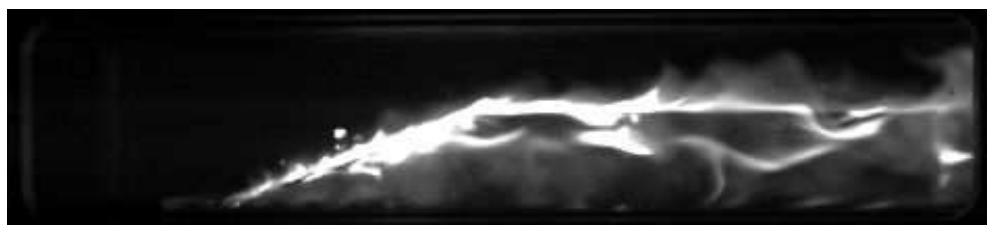

Figure 14 Image of HDPE during test 159 (5000 FPS, frame 3589)

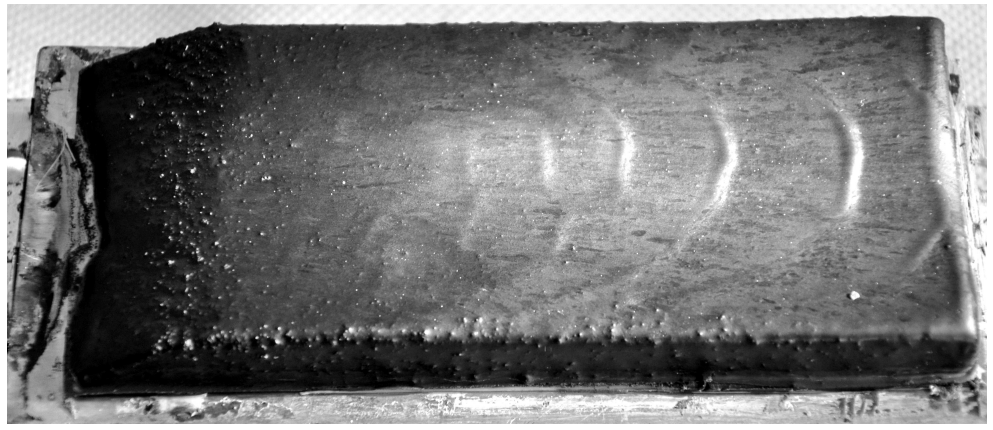

Figure 15 Fuel sample of $0907+2 \% \mathrm{CB}+10 \%$ SA after test 97

of the fuel where the igniter hits the fuel slab. When the paraffin is fully burning, the flame is too bright. Thus, only some thicker droplets can be seen which are released from near the burning surface but no fine droplets and structures like during ignition.

As a reference, HDPE has also been used in a further test campaign [24]. An example is shown in Fig. 14. Here, almost no droplet entrainment was visible during the tests. The flames also show wave behavior. Also, HDPE is expected to form a liquid layer, but high viscosity prevents entrainment.

Figure 15 shows an image of a fuel sample after the combustion test. Here, one can also see some residual wave like structure on the surface. These structures appeared on most of the recovered fuel samples, for the mixtures and, also, the pure samples. It is likely that this structure can be linked to the combustion behavior of the paraffin samples and the wave like flame structure. But one should also consider that $N_{2}$ purge flow was initiated at the end of the test to end the combustion and purge the pipes. This might have also influenced the surface of the paraffin.

The pressure of 1 bar in the current combustion chamber is still subcritical for the paraffins which are used [21]. Thus, a liquid melt layer is expected. This is in agreement with the huge droplet entrainment which was measured optically in the tests. At higher pressures, the paraffin would be in supercritical conditions 
and a pyrolysis layer is expected on top of the liquid layer [11]. This could change the liquid layer instabilities and also the entrainment process. But according to Karabeyoglu et al. [8], no pressure effects on the regression rate are expected for typical operating pressures. This has been stated due to measured regression rate data during tests, but no clear optical investigations at higher pressure have been made until now.

\section{CONCLUDING REMARKS}

Experimental characterization has been done with paraffin fuels that can be used for high regression rate applications. Optical investigations of the entrainment process have been done with high quality. The entrainment process for lowviscosity fuels shows a huge amount of very fine droplets being released from the surface and, thereby, enabling high regression rates. A wide database concerning viscosity, surface tension, burning rate data, and optical measurements has been established. The regression rate data collected so far indicate an increasing regression rate for decreasing viscosity of the liquid paraffin. These results show the same qualitative trend as with $2 \mathrm{D}$ radial burning rate tests done at SPLab with the same fuels [1]. Viscosity data show big differences depending on the paraffin type and type and amount of additives. At higher CB percentages, the mixtures show non-Newtonian behavior where the viscosity of the mixture depends also on the applied shear rates. The differences in surface tension between different paraffin samples are smaller and, thus, are less influencing on the regression rate.

\section{ACKNOWLEDGMENTS}

The support of the M11 team and the Department of Propellants is greatly acknowledged. Furthermore, we would like to thank W. Clauss from the DLR Lampoldshausen for his support, sharing his expertise in optical diagnostics and also providing the high-speed camera and optical equipment for the burning tests.

\section{REFERENCES}

1. Toson, E., M. Kobald, S. Di Betta, L. T. De Luca, H. Ciezki, and S. Schlechtriem. 2013. Rheological and ballistic investigations of paraffin-based fuels for hybrid rocket propulsion using a $2 \mathrm{~d}$ radial micro-burner. 5th European Conference for Aeronautics and Space Sciences. Munich, Germany. 
2. Humble, R.W., G. N. Henry, and W. J. Larson. 1995. Space propulsion analysis and design. Space technology ser. McGraw-Hill, Inc. 768 p.

3. Carrick, P. G., and C. W. Larson. 1995. Lab scale test and evaluation of cryogenic solid hybrid rocket fuels. AIAA Paper No. 95-2948.

4. Larson, C. W., K. L. Pfeil, M.E. DeRose, and P. G. Garrick. 1996. High pressure combustion of cryogenic solid fuels for hybrid rockets. AIAA Paper No. 1996-2594.

5. DeRose, M. E., K. L. Pfeil, P. G. Carrick, and C. W. Larson. 1997. Tube burner studies of cryogenic solid combustion. AIAA Paper No. 1997-3076.

6. Karabeyoglu, M. A., D. Altman, and B. J. Cantwell. 2002. Combustion of liquefying hybrid propellants: Part 1. General theory. J. Propul. Power 18(3):610-620.

7. Karabeyoglu, M. A., and B. J. Cantwell. 2002. Combustion of liquefying hybrid propellants: Part 2. Stability of liquid films. J. Propul. Power 18(3):621-630.

8. Karabeyoglu, M. A., G. Zilliac, B. J. Cantwell, S. DeZilwa, and P. Castellucci. 2004. Scale-up tests of high regression rate paraffin-based hybrid rocket fuels. J. Propul. Power 20(6):1037-1045.

9. Gater, R. A., and M. R. L. L'Ecuyer. 1970. A fundamental investigation of the phenomena that characterize liquid film cooling. Int. J. Heat Mass Transfer 13(3):19251939.

10. Nigmatulin, R., B. Nigmatulin, Y.A. Khodzaev, and V. Kroshilin. 1996. Entrainment and deposition rates in a dispersed-film flow. Int. J. Multiphase Flow 22(1):19-30.

11. Karabeyoglu, M. A., B. J. Cantwell, and J. Stevens. 2005. Evaluation of homologous series of normal-alkanes as hybrid rocket fuels. AIAA Paper No. 2005-3908.

12. Nakagawa, I., and S. Hikone. 2011. Study on the regression rate of paraffin-based hybrid rocket fuels. J. Propul. Power 27(6):1276-1279.

13. Maruyama, S., T. Ishiguro, K. Shinohara, and I. Nakagawa. 2011. Study on mechanical characteristic of paraffin-based fuel. AIAA Paper No. 2011-5678.

14. Karabeyoglu, M. A. 1998. Transient combustion in hybrid rockets. PhD Thesis. Stanford University.

15. Chandler, A., B. J. Cantwell, G. S. Hubbard, and G. Zilliac. 2011. Visualization of the liquid layer combustion of paraffin fuel. 62nd Astronautical Congress (International). Cape Town, South Africa. IAC-11-C.4.2.8.

16. Chandler, A., E. Jens, B. J. Cantwell, and G. S. Hubbard. 2012. Visualization of the liquid layer combustion of paraffin fuel for hybrid rocket applications. AIAA Paper No. 2012-3961.

17. DeLuca, L. T., L. Galfetti, F. Maggi, et al. 2011. An optical time-resolved technique of solid fuels burning for hybrid rocket propulsion. AIAA Paper No. 2011-5753.

18. Thumann, A., and H.K. Ciezki. 2002. Comparison of PIV and colour-schlieren measurements of the combustion process of boron particle containing solid fuel slabs in a rearward facing step combustor. Int. J. Energetic Mater. Chem. Propul. 5(1-6):742-752.

19. Ciezki, H.K., J. Sender, W. Clauss, A. Feinauer, and A. Thumann. 2003. Combustion of solid-fuel slabs containing boron particles in step combustor. J. Propul. Power 19(6):1180-1191. 
20. Marano, J. J., and G. D. Holder. 1997. General equation for correlating the thermophysical properties of $n$-paraffins, $n$-olefins, and other homologous series. 3 . Asymptotic behavior correlations for thermal and transport properties. Ind. Eng. Chem. Res. 36(5):2399-2408.

21. Marano, J. J., and G. D. Holder. 1997. General equation for correlating the thermophysical properties of $n$-paraffins, $n$-olefins, and other homologous series. 2 . Asymptotic behavior correlations for PVT properties. Ind. Eng. Chem. Res. 36(5):18951907.

22. Carissimi, J. 2012. Investigation of physical properties of paraffin based hybrid rocket fuels. Milan, Italy: Politecnico di Milano. Master Thesis.

23. Karabeyoglu, M. A., B. J. Cantwell, and G. Zilliac. 2007. Development of scalable space-time averaged regression rate expressions for hybrid rockets. J. Propul. Power 23(4):737-747.

24. Kobald, M., and S. Schlechtriem. 2013. Investigation of different hybrid rocket fuels in a 2D slab burner with optical techniques. 10th Conference (International) on Flow Dynamics. Sendai, Japan.

25. Kim, S., J. Lee, H. Moon, H. Sung, J. Kim, and J. Cho. 2010. Effect of paraffinLDPE blended fuel in hybrid rocket motor. AIAA Paper No. 2010-7031. 